Short Communication

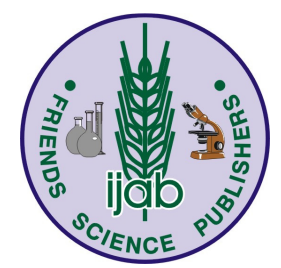

\title{
In vitro Multiple Shoot Induction in Soybean
}

\author{
Phetole Mangena, Phatlane William Mokwala and Roumiana Vassileva Nikolova* \\ Department of Biodiversity, School of Molecular and Life Sciences, Faculty of Science and Agriculture, University of \\ Limpopo, Private Bag X 1106, Sovenga 0727, South Africa \\ *For correspondence: Roumiana.Nikolova@ul.ac.za; nikolovarv@yahoo.com
}

\begin{abstract}
Genetic transformation is a crucial tool for cultivar improvement; however, soybean is regarded as highly recalcitrant and the success of transformation is affected by the explant source and the rate of in vitro shoot regeneration. Multiple shoot induction on soybean (Glycine max L.) cultivar LS 677 was carried out using single and double coty-node explants from soybean seedlings derived from seeds germinated on Murashige and Skoog (MS) culture media containing different concentrations of $\mathrm{N}^{6}$-benzyladenine (BA) and BA in combination with kinetin (KIN). Seedlings obtained from cytokinin treatments $\left(2-4\right.$ mg $\mathrm{L}^{-1}$ BA) were stronger with thick hypocotyls, reduced epicotyls and primary roots with few or no lateral root formation. These seedlings showed a better potential as a source for excision of explants than the thin, elongated control seedlings grown on MS medium without cytokinins. The highest number of multiple shoots, from both explant types, was obtained on MS media supplemented with 1.57 and $2.00 \mathrm{mg} \mathrm{L}^{-1}$ BA. The induced shoots were efficiently elongated and rooted on MS medium without plant growth regulators (PGRs). Rooted plantlets were acclimatised under controlled conditions with $70 \%$ success and produced viable seeds. The results of this study indicate that the soybean double coty-node explants derived from cytokinin treated seedlings could be a better explant source for in vitro shoot multiplication than the single coty-node explants. (C) 2015 Friends Science Publishers
\end{abstract}

Keywords: Double coty-nodes; Multiple shoot induction; Single coty-nodes; Soybeans

\section{Introduction}

Soybean transformation has been the subject of intense genetic research over the past few years. Agrobacteriummediated transformation using immature cotyledons (Yan et al., 2000) and axillary meristematic tissues (Zeng et al., 2004) obtained from soybean seedlings are the predominantly tested methods due to explants' morphogenetic potentiality. The earliest research on soybean transformation attempted to improve in vitro shoot regeneration and transformation frequencies (Wright et al., 1986; Paz et al., 2004). However, routine genetic transformation of soybean is still difficult to achieve because of possible chimerism, explant- and genotypespecific transformation (Yan et al., 2000; Liu et al., 2008).

Cotyledonary and nodal explants, with or without axillary buds, from different crops have been used with success for in vitro multiple shoot induction in the presence of thidiazuron (TDZ) or BA (De-Carvalho, 2000; Radhakrishnan et al., 2009). Regeneration frequency greater than $50 \%$ was attained from mature cotyledonary explants in the presence of BA $(\geq 10 \mu M)$ alone or in combination with TDZ $(\geq 5 \mu M)$ (Malik and Saxena, 1992; Kaneda et al., 1997). Franklin et al. (2004) reported 84 and 37\% shoot regeneration frequencies from explants derived from cotyledons of mature and immature seeds respectively, when TDZ $(4.54 \mu M)$ was used in combination with BA (13.3 $\mu M)$. However, pretreatment and maintenance of cultures on media containing TDZ may cause abnormal changes in the growth and development of plants such as hyperhydricity, short and compact shoots, difficulty in shoot elongation and rooting of the recovered shoots (Lu, 1993; Huetteman and Preece, 1993).

$\mathrm{Ma}$ and $\mathrm{Wu}(2008)$ reported that the highest number of shoots (30-35) per explants of four soybean cultivars (Jilin 35, Dongnong 42, Hefeng 25, and Hefeng 41) were recorded on MS media supplemented with Gamborg's B5 vitamins (MSB5), BA (3.0 mg L $\left.{ }^{-1}\right)$, IBA $\left(0.2 \mathrm{mg} \mathrm{L}^{-1}\right)$ and KIN $\left(0.5 \mathrm{mg} \mathrm{L}^{-1}\right)$. Strides made using soybean coty-node explants with one axillary meristem supported by a single cotyledon have so far not overcome the difficulties in developing a routine and reproducible in vitro regeneration protocol. Therefore, the challenge in soybean improvement remains to be the lack of efficient regeneration method, especially one, which is compatible with the genetic transformation of this crop via A. tumefaciens.

Cytokinins have been reported to facilitate in vitro shoot multiplication through bud initiation and continuous support of bud growth into adventitious shoots (DeCarvalho, 2000). The aim of this study was then, to 
investigate the effect of different concentrations of BA and $\mathrm{BA}$ in combination with $\mathrm{KIN}$ on in vitro seed germination, seedling development and multiple shoot induction on single and double coty-node explants of soybean (Glycine max L.) cultivar LS 677 as a precursor protocol to Agrobacterium-mediated genetic transformation.

\section{Materials and Methods}

\section{Plant Material}

Soybean [Glycine max (L.) Merrill cultivar LS 677] seeds were purchased from Link Seed South Africa.

\section{In vitro Seed Germination and Seedling Development}

The seeds were first washed with soapy water, rinsed with running tap water for 5-10 min, dried with a clean tissue paper and then sterilised using chlorine gas for $16 \mathrm{~h}$. The sterilised seeds were inoculated on MS media containing $3 \%$ sucrose, $0.3 \%$ gelrite and supplemented with with different concentrations of BA $\left(1.57,2.00,4.00 \mathrm{mg} \mathrm{L}^{-1}\right)$ alone and BA (2.00 mg L $\left.\mathrm{m}^{-1}\right)$ in combination with KIN (1.00 $\left.\mathrm{mg} \mathrm{L}^{-1}\right)$. Plant growth regulators-free MS medium was used as a control. The cultures were incubated for 8-10 days under controlled growth conditions to obtain seedlings with completely open cotyledons.

\section{Explant Preparation and Shoot Induction}

Two types of coty-node explants (single or double cotynodes) were prepared from the seedlings. Double coty-node explants were obtained by excising out the epicotyls at the cotyledonary junctions and cutting off the hypocotyls 4-5 $\mathrm{mm}$ beneath the cotyledons. For single coty-node explants, seedlings were split in the middle of the hypocotylcotyledon junction. Explants were sub-cultured on MS media supplemented with the same cytokinins concentration/combination as those used for germination. Hormone free MS medium was used as a control. Thirty explants per hormonal treatment were used and the experiment was repeated four times. The number of induced shoots per explant was recorded weekly.

\section{Shoot Elongation and Rooting}

The in vitro developed multiple shoots from each explant were excised and cultured on MS medium supplemented with $0.5 \mathrm{mg} \mathrm{L}^{-1} \mathrm{BA}$ and $0.6 \mathrm{mg} \mathrm{L}^{-1} \mathrm{GA}_{3}$ for $2-3$ weeks. Elongated shoots were rinsed in sterile distilled water and sub-cultured for rooting on MS medium containing $0.5 \mathrm{mg}$ $\mathrm{L}^{-1}$ of indole-3-butyric acid (IBA) and $1.2 \mathrm{mg} \mathrm{L}^{-1}$ of indole acetic acid (IAA) and on PGR-free MS medium.

\section{Plant Acclimatization}

In vitro rooted plantlets $(40-60 \mathrm{~mm}$ in height) were transferred into $150 \mathrm{~mL}$ culture bottles quarter-filled with sterile vermiculite and covered with transparent plastic bags. The plastic bags were punctured and gradually opened to allow the plants to acclimatise. Plants were watered once a week with modified Hoagland nutrient solution (Epstein, 1972). Acclimatised plants were transplanted into plastic pots $(10-15 \mathrm{~cm})$ and maintained under controlled growth conditions until flowering and fruit pod maturity.

\section{Growth Conditions}

All in vitro cultures were kept in a growth room at $24 \pm 2^{\circ} \mathrm{C}$ and $16 \mathrm{~h}$ photoperiod of $50-60 \mu \mathrm{mol} \mathrm{m} \mathrm{m}^{-2} \mathrm{~s}^{-1}$ light intensity. The in vitro produced plantlets were acclimatised under controlled conditions at $24 \pm 2^{\circ} \mathrm{C}$ and $16 \mathrm{~h}$ photoperiod of 160-200 $\mu \mathrm{mol} \mathrm{m}^{-2} \mathrm{~s}^{-1}$ light intensity.

\section{Data Analysis}

Data on the number of shoots per explant were recorded and analyzed using one-way ANOVA with SPSS 20 for Windows. Frequency in percentages was calculated as described by Ma and Wu (2008).

\section{Results}

\section{In-vitro Seed Germination and Seedling Development}

Soybean seeds germinated (90-100\%) within 3 days of incubation in all treatments. Seedlings differed significantly among the treatments. Those obtained from the cytokinin treatments showed high survival rate (86.7-95.6\%), thickening of hypocotyls, strong reduction of epicotyls and roots with few or no lateral root formation (Fig. 1B-E). The thickest hypocotyls (4-5 $\mathrm{mm}$ in diameter) were observed on media containing $4.00 \mathrm{mg} \mathrm{L}^{-1} \mathrm{BA}$ (Fig. 1D), in contrast to seedlings from the other cytokinin treatments $(3-4 \mathrm{~mm})$ (Fig. 1B, C and E). Control seedlings had lower survival rate $(67.8 \%)$ and produced thin $(1-2 \mathrm{~mm}$ in diameter) elongated hypocotyls, epicotyls and primary roots with lateral roots (Fig. 1A), as compared to the strong seedlings derived from cytokinin-treated seeds, especially with 2.00 and $4 \mathrm{mg} \mathrm{L}^{-1} \mathrm{BA}$ (Fig. $1 \mathrm{C}$ and D).

\section{Multiple Shoot Induction from Single and Double Coty- Node Explants}

Multiple shoots were directly induced from single and double coty-node explants using BA and BA in combination with KIN. The frequency of shoot formation was influenced by both explant type and the cytokinin concentration and combination. All cytokinin treatments, after 14 days of incubation, produced significantly higher number of shoots from double coty-node explants as compared to the control, without PGRs (Table 1). The highest number of shoots, with a mean of 7.93 shoots per explant, was obtained from the treatment with $2 \mathrm{mg} \mathrm{L}^{-1} \mathrm{BA}$ (Table 1). 
Table 1: Shoot induction on single and double coty-node explants in response to different concentrations and combinations of cytokinins after 21 days of culture on MS media

\begin{tabular}{lccccc}
\hline \multicolumn{2}{l}{ Cytokinin treatments mg L } & \multicolumn{2}{c}{ Mean number of shoots per coty-node explant } & \multicolumn{2}{c}{ Frequency $(\%)$ of shoot induction per coty-node explant* } \\
\hline BA & KIN & SCN & DCN & SCN & DCN \\
\hline 1.57 & 0.00 & $3.87^{\mathrm{b}}$ & $7.00^{\mathrm{a}}$ & $36.7^{\mathrm{b}}$ & $83.3^{\mathrm{a}}$ \\
2.00 & 0.00 & $5.27^{\mathrm{a}}$ & $7.93^{\mathrm{a}}$ & $56.7^{\mathrm{a}}$ & $80.0^{\mathrm{b}}$ \\
4.00 & 0.00 & $1.87^{\mathrm{c}}$ & $5.00^{\mathrm{c}}$ & $10.0^{\mathrm{d}}$ & $50.0^{\mathrm{d}}$ \\
2.00 & 1.00 & $2.00^{\mathrm{c}}$ & $6.27^{\mathrm{b}}$ & $13.3^{\mathrm{c}}$ & $73.3^{\mathrm{c}}$ \\
0.00 & 0.00 & $1.27^{\mathrm{d}}$ & $2.13^{\mathrm{d}}$ & $0.00^{\mathrm{e}}$ & $0.00^{\mathrm{e}}$ \\
\hline
\end{tabular}

$\mathrm{BA}=\mathrm{N}^{6}$-benzyladenine, $\mathrm{KIN}=$ kinetin, $\mathrm{SCN}=$ single coty-node, $\mathrm{DCN}=$ double coty-node, Values within columns followed by the same letters are not significantly different at the 5\% confidence level, *Frequency of shoot induction $=($ No of explants with three or more shoots/total no of explants) $\times 100$

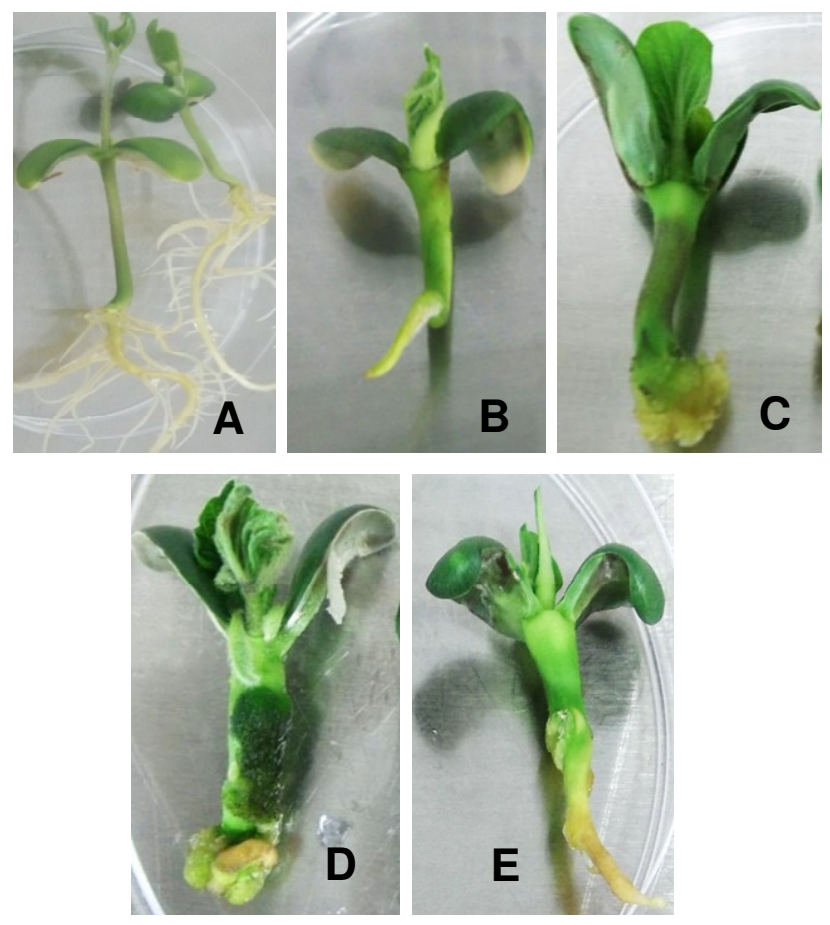

Fig. 1: Seedling developed on PGR-free MS culture medium (A) and on MS media supplemented with $1.57 \mathrm{mg}$ $\mathrm{L}^{-1} \mathrm{BA}(\mathrm{B}), 2.00 \mathrm{mg} \mathrm{L}^{-1} \mathrm{BA}(\mathrm{C}), 4.00 \mathrm{mg} \mathrm{L}^{-1} \mathrm{BA}(\mathrm{D}), 2.00$ $\mathrm{mg} \mathrm{L^{-1 }} \mathrm{BA}+1.00 \mathrm{mg} \mathrm{L}^{-1} \mathrm{KIN}(\mathrm{E})$ after 7 days of incubation

Although there was no significant difference in the number of shoots induced by $1.57 \mathrm{mg} \mathrm{L}^{-1}$ and $2 \mathrm{mg} \mathrm{L}^{-1} \mathrm{BA}$, shoots derived from $2 \mathrm{mg} \mathrm{L}^{-1} \mathrm{BA}$ treatment were stronger and responded better to elongation and rooting (Fig. 2A-B). A similar shoot induction response, with respect to the same cytokinin treatments, was observed with the single cotynode explants (Fig. 2D-E) where the highest number (5.27) of shoots was obtained on MS medium with $2 \mathrm{mg} \mathrm{L}^{-1} \mathrm{BA}$ (Table 1).

The treatment of both types of explant with a higher concentration of BA $\left(4 \mathrm{mg} \mathrm{L}^{-1}\right)$ alone or BA $(2 \mathrm{mg}$ $\left.\mathrm{L}^{-1}\right)$ in combination with $\mathrm{KIN}\left(1 \mathrm{mg} \mathrm{L}{ }^{-1}\right)$ lead to a lower number of shoot production per single (1.87-2) and double coty-node (5-6.27) explants (Table 1). This response was

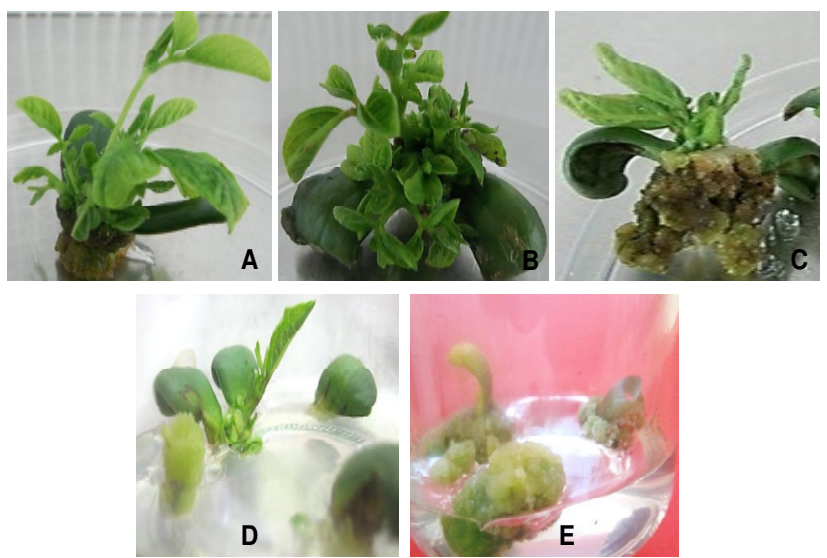

Fig. 2: Examples of multiple shoot and/or callus induction on double coty-node explants cultured on MS media supplemented with $1.57 \mathrm{mg} \mathrm{L}^{-1}$ BA (A), $2.00 \mathrm{mg} \mathrm{L}^{-1} \mathrm{BA}$ (B), $4.00 \mathrm{mg} \mathrm{L}^{-1} \mathrm{BA}(\mathrm{C})$ and on single coty-node explants cultured on MS media supplemented with $2 \mathrm{mg} \mathrm{L}^{-1} \mathrm{BA}$ (D) and $4.00 \mathrm{mg} \mathrm{L}^{-1} \mathrm{BA}(\mathrm{E})$, respectively
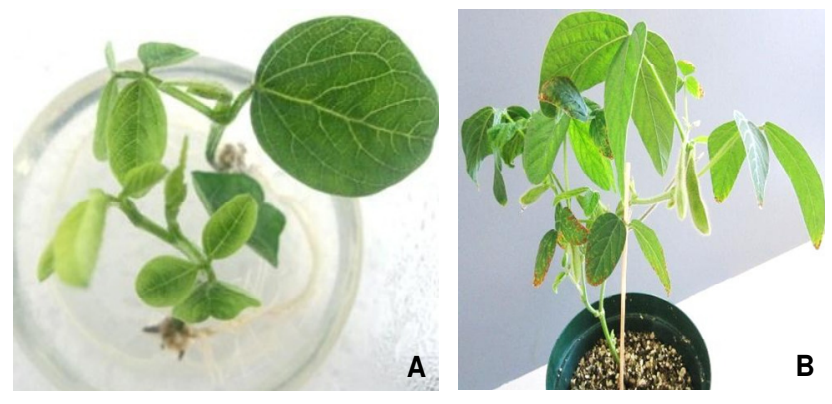

Fig. 3: Rooting of elongated shoots on MS medium without hormones after two weeks of culture (A). Regenerated plants with seed pods (B)

accompanied by massive callus induction, which was more pronounced on single coty-node explants (Fig. 2E), as compared to the double coty-node explants (Fig. 2C). Depending on the cytokinin concentration, the single cotynode explants showed lower frequency $(10-57 \%)$ of shoot induction, as compared to the double coty-nodes (50-83\%) within 3 weeks of culture (Table 1). 


\section{Shoot Elongation and Rooting}

Multiple shoot clumps elongated over 20 days of culture on MS medium containing $0.6 \mathrm{mg} \mathrm{L}^{-1} \mathrm{GA}_{3}$ resulting in weak shoots, while the transfer of shoot clumps to PGR-free MS medium resulted in stronger shoots and elongation occurred within 15 days of culture. Elongated shoots were more efficiently rooted on MS medium without PGRs (Fig. 3A) as compared to MS medium supplemented with $0.5 \mathrm{mg} \mathrm{L}^{-1}$ of indole-3-butyric acid (IBA) and $1.2 \mathrm{mg} \mathrm{L}^{-1}$ of indole acetic acid (IAA), which resulted in delayed rooting and masses of callus formation at the base of the cut stems.

\section{Plant Acclimatization}

Rooted plants were successfully acclimatized under controlled growth conditions over a period of 3-4 weeks attaining $70 \%$ survival rate. The acclimatized plants grew to maturity, flowered and produced fruits (Fig. 3B).

\section{Discussion}

The effect of PGRs on in vitro seedling growth and development of a suitable explant source for multiple shoot induction remains insufficiently assessed. Some reports show the effect of PGRs such as $\left(\mathrm{GA}_{3}\right)$ on seed germination, seedling growth and crop yield (Malik and Saxena, 1992; Zhang et al., 1999; Hamayun et al., 2010). Few link seed hormonal treatment to multiple shoot induction (Shan et al., 2005; $\mathrm{Ma}$ and $\mathrm{Wu}, 2008$ ). According to our study, although the presence of cytokinins in the germination medium had no effect on the in vitro soybean germination; seedling growth was affected by higher concentrations of BA (2$4.00 \mathrm{mg} \mathrm{L}^{-1}$ ) resulting in development of thicker seedlings which proved to be a better source for excisions of explants for multiple shoot induction in comparison to seedlings developed on PGR free-medium. These explants were also suitable for making incisions for infection with agrobacteria during genetic transformation (unpublished data). Malik and Saxena (1992) reported that pretreatment of Phaseolus vulgaris seeds with BA in combination with TDZ resulted in the development of stout seedlings from which multiple shoots could be stimulated. Our results showed that, multiple shoots can be directly induced from single and double coty-node explants of soybean (Glycine max L.) cultivar LS 677 using BA and BA in combination with KIN. However, the frequency of shoot formation in vitro was influenced by both explant type and the cytokinin concentration and combination. The highest mean number (7.93) of shoots per explant was obtained from double cotynode explant treated with $2 \mathrm{mg} \mathrm{L}^{-1}$ BA. Shan et al. (2005) obtained a maximum of 6 shoots per explant when explants were treated with $0.1 \mathrm{mg} \mathrm{L}^{-1} \mathrm{TDZ}$. Their explants were the cotyledonary nodes, with the epicotyl, hypocotyl and cotyledons removed. The explants produced multiple buds, which could be further used to produce shoots or more multiple bud tissues. On the other hand, Ma and Wu (2008) reported a mean of 33 shoots per explant when whole cotyledonary node explant for soybean cultivar Hefeng 25 was pre-treated with $0.4 \mathrm{mg} \mathrm{L}^{-1} \mathrm{BA}$. However, in their case shoot buds were not allowed to develop on the explant but were excised and sub-cultured.

Our observations showed that the treatments of both type of explants with a higher concentration of BA $(4 \mathrm{mg}$ $\left.\mathrm{L}^{-1}\right)$ or BA in combination with $\mathrm{KIN}\left(2 \mathrm{mg} \mathrm{L}^{-1} \mathrm{BA}+1 \mathrm{mg}\right.$ $\mathrm{L}^{-1} \mathrm{KIN}$ ) lead to a lower number of shoots accompanied by massive callus formation. These results suggest that there was no synergism caused by the combination of BA with KIN for multiple shoot induction as was the case with Malik and Saxena (1992), where the combination of BA (80 $\mu M)$ with KIN $(10 \mu M)$ was also ineffective in increasing shoot induction. In contrast, Franklin et al. (2004) found that BA $(13.3 \mu M)$ in combination with TDZ (4.54 $\mu M$ ) increased regeneration rate to $84 \%$ from their individual respective rates of $50 \%$ and $68 \%$. Previous studies have shown that, when BA is combined with TDZ, shoot formation can be attributed to TDZ alone rather than BA, or both (Wright et al., 1986; Khalafalla and Hattori, 1999).

The massive callus initiation observed in the presence of a high BA concentration or in combination with KIN was more pronounced on single coty-node explants as compared to the double coty-node explants suggesting that nonmorphogenic competent cells were induced to divide by severe wounding during explant preparation. $\mathrm{Ma}$ and $\mathrm{Wu}$ (2008) suggested that explant damage during excision of cotyledonary nodes can easily cause dedifferentiation into callus if sub-cultured on media supplemented with high concentrations $\left(>3 \mathrm{mg} \mathrm{L}^{-1}\right)$ of BA. The callus will compete with axillary meristems for nutrient adsorption, which will eventually have negative effects on shoot growth.

The high shoot regeneration frequency obtained on double coty-node explants may be due to the two meristematic regions present on the explants, as compared to vertically split single cotyledons (Zhang et al., 1999). Polisetty et al. (1997) also demonstrated that multiple shoots are not efficiently produced, when only embryonic axes with axillary buds, without both cotyledons supporting the tissue explants are used. The presence of the cotyledons appeared to support the survival and growth of shoots. Franklin et al. (2004) reported high frequency of shoot induction from hypocotyl segments than from cotyledonary nodes at $9.04 \mu \mathrm{M}$ TDZ in soybean cv. Bonminori. Their report suggested that explant responses to shoot induction depends on growth regulator concentration or the genotype.

Our in vitro induced multiple shoots elongated and developed better when subcultured as clumps, than as excised individual shoots. Addition of $\mathrm{GA}_{3}$ into the medium had no positive effect on plant growth since it resulted in weaker shoots, as compared to shoots elongated on PGRfree MS medium. Rooting of elongated shoots also was more efficient on MS medium without PGRs than in the presence of auxin, which induced callus formation at the 
base of the shoots. In contrast, Islam et al. (2005) reported production of roots in in vitro Cicer root culture using $0.5-$ $0.75 \mathrm{mg} \mathrm{L}^{-1}$ IBA. The relatively easy acclimatization and the high survival rate of in vitro produced plantlets obtained in this study pave the way for routine in vitro propagation of soybean.

\section{Conclusion}

The results of this study show that germination of soybean seeds on MS culture medium with BA in the range of 2-4 $\mathrm{mg} \mathrm{L}^{-1}$ is suitable for establishing strong seedlings that can be used directly as a reliable and aseptic explant source for in vitro shoot multiplication on MS medium. The high shoot regeneration frequency obtained on double coty-node explants on MS medium supplemented with $2 \mathrm{mg} \mathrm{L}^{-1} \mathrm{BA}$ indicates that the explants have a potential in genetic transformation and will be tried in a subsequent study.

\section{Acknowledgements}

We are grateful to the Department of Biodiversity, University of Limpopo, and the National Research Foundation (NRF) of South Africa for the financial support of this study.

\section{References}

De-Carvalho, M.H.C., B. Van-Le, Y. Zuily-Fodil, T.T.P. Thi and K.T.T. Van, 2000. Efficient whole plant regeneration of common bean (Phaseolus vulgaris L.) using thin-cell-layer culture and silver nitrate. Plant Sci., 157: 233-232

Epstein, E., 1972. Mineral Nutrition of Plants: Principles and Perspectives, p: 70. John Wiley and Sons, New York, USA

Franklin, G., L. Capenter, E. Davis, C.V. Reddy, D. Al-Abed, W. AbouAlaiwi, M. Parani, B. Smith, S.L Goldman and R.V. Sairam, 2004 Factors influencing regeneration of soybean from mature and immature cotyledons. Plant Cell Tiss. Organ. Cult., 43: 73-79

Hamayun, M., S.A. Khan, A.L., Khan, J.H., Shin, B. Ahmed, D.H. Shin and I.J. Lee, 2010. Exogenous gibberellic acid reprograms soybeans to higher growth and salt stress tolerance. J. Agric Food Chem., 12: 7226-7232

Huetteman, C.A. and J.E. Preece, 1993. Thidiazuron: A potent cytokinin for woody plant tissue culture. Plant Cell Tiss. Org. Cult., 33: 105119
Islam, M.A., H. Zubair, I. Nisbah and F. Chaudhary, 2005. Effect of different plant growth regulators for the economical production of in vitro root cultures of Cicer arietinum L. Int. J. Agric. Biol., 7: 621-626

Kaneda, K., Y. Tabei, S. Nishimura, K. Harada, T. Akihama and K. Kitamura, 1997. Combination of thidiazuron and basal media with low salt concentrations increases the frequency of shoot organogenesis in soybeans [Glycine max (L.) Merrill.]. Plant Cell Rep., 17: 8-12

Khalafalla, M.M. and K. Hattori, 1999. A combination of thidiazuron and benzyladenine promotes multiple shoot production from cotyledonary node explants of faba bean (Vicia faba L.). J. Plant Growth Regul., 27: $145-148$

Liu, S.J., Z.M. Wei and J.Q. Huang, 2008. The effect of co-cultivation and selection parameters on Agrobacterium-mediated transformation of Chinese soybean varieties. Plant Cell Rep., 27: 489-498

Lu, C.Y., 1993. The use of thidiazuron in tissue culture. In Vitro Cell Dev. Biol., 29: 92-96

Ma, X.H. and T.L. Wu, 2008. Rapid and efficient regeneration in soybean [Glycine max (L.) Merrill] from whole cotyledonary node explants. Acta Physiol Plant., 30: 209-216

Malik, K.A. and P.K. Saxena, 1992. Regeneration in Phaseolus vulgaris L.: high-frequency induction of direct shoot formation in intact seedlings by $n^{6}$-benzyaminopurine and thidiazuron. Planta, 186: 384-389

Paz, M.M., S. Huixia, G. Zibiao, Z. Zhang, K.B. Anjan and K. Wang, 2004. Assessment of conditions affecting Agrobacterium-mediated soybean transformation using the cotyledonary node explants. Plant Sci., 136: $167-179$

Polisetty, R., V. Paul, J.J. Deveshwar, S. Khetarpal, K. Suresh and R. Chandra, 1997. Multiple shoot induction by benzyladenine and complete plant regeneration from seed explant of chickpea (Cicer arietinum L.). Plant Cell Rep., 16: 565-571

Radhakrishnan, R., A. Ramachandran and B.D.R. Kumari, 2009. Rooting and shooting: Dual functions of thidiazuron in in vitro regeneration of soybean (Glycine max. L.). Acta Physiol. Plant., 31: 1213-1217

Shan, Z., K. Raemakers, N.E. Tzitzikas, Z. Ma and R.G.F. Visser, 2005. Development of a highly efficient, repetitive system of organogenesis in soybean (Glycine max (L.) Merr). Plant Cell Rep., 24: 507-512

Wright, M.S., S.M. Koehler, M.A. Hinchee and M.G, Carnes, 1986. Plant regeneration by organogenesis in Glycine max L. Plant Cell Rep., 5: $150-154$

Yan, B., M.S.S. Reddy, G.B. Collins and R.D. Dinkins, 2000. Agrobacterium tumefaciens-mediated transformation of soybean [Glycine max (L.) Merr.] using immature zygotic cotyledon explants. Plant Cell Rep., 10: 1090-1097

Zeng, P., D.A. Vadnais, Z. Zhang and Polacco, 2004. Refined glufosinate selection in Agrobacterium-mediated transformation of soybean [Glycine max (L.) Merrill]. Plant Cell Rep., 22: 478-487

Zhang, Z., A. Xing, P. Staswick and T. Clemente, 1999. The use of glufosinate as selective agent in Agrobacterium-mediated transformation of soybean. Plant Cell Tiss. Org. Cult., 56: 37-46

(Received 26 February 2014; Accepted 15 September 2014) 